\title{
A Study Among the Social Capital Types and Self-concept of Facebook User
}

\author{
Certeza, Carlo B and Oli, Lovely Joy D.
}

\begin{abstract}
Today Facebook is considered as one of the most popular platforms for online social networking among adolescence. The purpose of this study is to recognize participants' social capital types as an indicator in using their Facebook in order to know their self-concept. The study was carried out in Our Lady of Fatima University - Valenzuela City with senior high school students (SHS) under of HUMMS section. Three questionnaires were designed to assess Bergen Facebook Addiction Scale, Internet Social Capital Scales and Robson's Self-Concept Questionnaire to the SHS and was administered to 200 students' selected using purposive sampling technique. Variables identified are dominant scoring on social capital types, dependency to Facebook and self-concept. The Pearson product-moment correlation coefficient was used to examine the relationship between Facebook Dependency and self-concept among bonding and bridging type. Furthermore, a T-Test was carried out to determine the relative difference of social capital types which are bonding and bridging type. An analysis of the results was carried out using the SPSS software package. And the findings of this study shows that the relationship of Facebook Dependency and selfconcept was not significantly correlated in both bonding and bridging type. Furthermore, there is no difference between bonding and bridging social capital types.
\end{abstract}

Keywords - Social Capital Types, Facebook, Facebook Usage, \& Self-concept.

\section{INTRODUCTION}

Looking back to how it was before, the innovation in adolescence way of communicating now has changed a lot. Individuals back then are more on traditional way in communicating a person, interacting with people and having a face-to-face conversation where you can see the facial expression and body gestures of the person you are talking to. While the adolescence nowadays, are more likely to be dependent in Facebook as a way of communication to their peers, family, love ones or even to a stranger. This claim was supported by the study of Igna (2015) [127] Philippines described as one of the highest consumption of hours in social media sites, especially Facebook with the average of 6 hours and 17 minutes via a PC or Tablet a day. Over 54,000,000 Facebook users in the Philippines. In particular, the report examines many fast-growth nations, which have some of the most enthusiastic and engaged internet users. South-East

Lovely Joy D. Oli, Student, Our Lady of Fatima University - Valenzuela Campus, Philippines,

Carlo B. Certeza , PhD Student, Our Lady of Fatima University, Philippines,
Asians register the highest average daily web use, with users in the Philippines getting online for more than 6 hours per day. (McGrath, 2015). [131] Another survey found in the study of Herring, Kapidzic (2015) [65] that almost teenagers in the United States ages 12-17 are online equivalent to $95 \%$, compare to an adult that has $78 \%$ only. It only means that outgrow of communicating through social media like Facebook was only recently. Currrently, Facebook is almost a decade but, still considered as the most influential social networking sites, even though there various social networking sites that become strong competitors. Facebook was still on the top on the list. According to Arendain \& Murcia (2016) [21], Philippines was marked as the top 8th Facebook users, only states that Facebook is prevalent in the Filipino society.

Social media site as a way of communication, selfexpression and self-promotion, what does it have to do with the adolescence's self-concept?

Facebook gives the individual the ability to make a positive impression to others or an impression that a similar to their ideal. Creating an online identity. Herring, \& Kapidzic, (2015) [65] Rauch et al. (2013) [94], stated that individual who's socially anxious find's Facebook as a safe space due to its distance barrier in reaching the similar others. It gives them a boost in their confidence since it's just a virtual communication that helps them improve their offline interactions. So, they prefer it more than the usual face to face communication. Using social networking sites like Facebook has been linked to other studies that might affect the behavior of a person. One study that has been linked to Facebook is the anxiety and antisocial behavior. In this study, researchers conclude that, person was inhibited using Facebook find it easier to interact with other people than in face-to-face social interaction.

Social capital is the process which people as a whole communicates with each other. It can be classifying as the bridging and bonding type. The bridging type like texting, chatting or using of social media like Facebook, considered as the virtual way of communicating and in terms of bridging social capital type, person who has low esteem gained more from their use of Facebook than with high self-esteem. Most of the adolescence nowadays are commonly used Facebook for interaction. Did they already forget the benefits of having a traditional way of communication? Or the conclusion that they prefer to have the trendy way is thru due to arousal and beneficial factors of Facebook to their self-concept? Facebook 
among the adolescence is prevalent due to individual who are socially anxious and insecure. Social Capital can be divided in two forms the bonding and bridging type which can both have a positive effect in well-being, life satisfaction and self-esteem (Hofer \& Aubert, 2013) [68].

Researchers came up to an idea of comparing the adolescence social capital, to know what communication they are used to; is it the bridging or bonding type of communication.

Whereas researchers conceptualization on the focus of the micro-level of social capital that will give researchers for a perfect view in socio-emotional support or benefits of social interactions for individuals.

\section{METHODOLOGY}

\section{A. Research Design}

A correlation-comparative design was utilized in this study to be able to determine if Facebook dependency is significant related to self-concept of the adolescence. Furthermore, to determine if there is a significant different among social capital types namely: bonding and bridging. A quantitative study, whereas the researchers used correlational-comparative design, to compare the types of social capital prior to the social networking sites, which is Facebook that is correlated to the self-concept of the participants.

Researchers use this design, for it will be the best way to determine the results in obtaining the difference of social capital types; bonding and bridging. Additional, correlation Facebook dependency of the adolescence and how it affects their self-concept as they will use the Facebook.

\section{B. Population and Sampling}

The researchers used the purposive sampling to obtain 200 senior high students of Our Lady of Fatima UniversityValenzuela Campus ranging from 14-21 years of age. (Erikson, 2012) [58], claims that this ages are in the stage of curiosity and social interaction to their peer and environment. He/she should be on "active" Facebook users during the last 30 days. In order to $\log$ in, e-mail address require username and password. Facebook users can socialize with their former colleagues, friends, join groups and post, like, share, and comment, they can also link with a wide selection of applications such as Instagram, Twitter, and etc., (Statistica.com, 2016) [118].

\section{Data Gathering Procedure}

In selecting the topic or planning the phase. The researchers want to know the impact of social capital among the adolescents in order to know the difference of the social capital between the two types of which are the "Bonding and Bridging." Researchers combine another variable to see the significant relationship. Self-concept and Facebook Dependency. The first two researchers are for the preliminary portion and for providing the theoretical framework. The second batch of two researchers of this study is for scrutinize the related review literatures to have background between the said variables, and to have essential understanding of the current study. The last batch of the two researchers were provide the statistical analysis and three instruments were administered.

Informed consent distributed to the respondents, the first tool was the Internet Social Capital Scales by Dr. Williams, to determine if the respondents are bridging or bonding type. (There will be no time limit in administering the test). (Lora et al.,, 2014) [79]. The second tool was Bergen Facebook Addiction Scale, whereas in this instrumentation, researchers will capable to have an idea if the respondent is dependent on Facebook in terms of communication. The last test administered the Self-Concept Questionnaire by Robson, this questionnaire is to determine the self-concept of an individual by using social interaction, and how the respondents affect their self-concept in using Facebook.

For the statistical analysis, the researchers use the Pearson-r to find out the significant relationship between the Facebook dependency and Self-concept. T-test monitored if there is a significant difference in comparing bonding and bridging type.

\section{ANALYSIS OF DATA}

\section{A. Figures and Tables}

TABLE I

\begin{tabular}{|c|c|c|c|}
\hline Variables & Mean & SD & Interpretation \\
\hline \multicolumn{4}{|l|}{ Bonding } \\
\hline Self-concept & 108 & 10.581 & AVERAGE LEVEL \\
\hline Facebook Users & 47 & 16.406 & MODERATE LEVEL \\
\hline \multicolumn{4}{|l|}{ Bridging } \\
\hline Self-concept & 113 & 13.214 & AVERAGE LEVEL \\
\hline Facebook Users & 46 & 16.953 & MODERATE LEVEL \\
\hline
\end{tabular}

Table 1 shows the standard deviation which, to recognize the dispersion which means of data or variables and also a basis on how it affected the mean in each variable that were closely relative to the dispersion of the mean. The data above showed that bonding and bridging type has the same self-concept and Facebook dependency level, which means that regardless of their social concept types, the respondents are meeting the typical needs of an adolescent in terms of self-concept. Furthermore, it means that the adolescent are clear with their goals, values and beliefs (Erikson, 1968) [58], which means that the respondents will have a very satisfying adulthood.

Cognitive development of adolescents allows to conceptualize and gained self-concept moderately in terms of interaction to share a common interest like new ways of communicating and sharing of ideas that received benefits through "bonding" and "bridging" that shows the moderation of using Facebook (Ellison, Steinfeld, \& Lampe., 2008) [104]. 
TABLE II

Table 2 Relationship of Facebook Users and Self-concept among Bridging type.

\begin{tabular}{lcccc}
\hline Variables & r-value & $\mathrm{p}$-value & Decision & Interpretation \\
\hline $\begin{array}{l}\text { Bridging Type } \\
\text { Facebook Users } \\
\text { Self-concept }\end{array}$ & .007 & .963 & Accept Ho & NO RELATIONSHIP \\
\hline
\end{tabular}

${ }^{*}$ Correlation is significant at the 0.01 level (2-tailed).

Table 2 above shows the correlation of Facebook dependency and self-concept of Bridging social capital types are varies with the $\mathrm{p}$-value results, low $\mathrm{p}$-values were more unlikely to prove with a true null hypothesis while, high p-values were likely to reject the hypothesis. And the researchers accept the null hypothesis that brings to a conclusion that there is no significant relationship between the Facebook and self-concept of Bridging type individuals.

Bridging type is not affected by intensity of Facebook use and did not find any relationship between bridging social capital on using Facebook, possible that there are such other factors, that can develop the self-concept of adolescents such as physical interaction and creating positive environment.

Additionally, bridging social capital type individuals' as described as individuals with no emotional attachment. Therefore, respondents show that their self-concept can develop without using Facebook or individuals with dependency symptoms because the self-concept of the adolescents are well-rounded in terms that they are responsible for their own choices.

TABLE III

Table 3 Relationship of Facebook Users and Self-concept among Bonding Type

\begin{tabular}{lcccc}
\hline Variables & r-value & p-value & Decision & Interpretation \\
\hline BondingType & & & & \\
Facebook Users & -.180 & .212 & Accept Ho & NO RELATIONSHIP \\
Self-concept & & & & \\
\hline *Correlation is significant at the 0.01 level (2-tailed).
\end{tabular}

Shows the correlation of Facebook dependency and selfconcept of Bonding social capital type which the researchers reject the null hypothesis that brings to a conclusion of there is no significant relationship between the Facebook and selfconcept of bonding type.

In terms of rejecting the hypothesis, $\mathrm{P}$ is the statistical measurement to described whether the hypothesis is significant or not significant, however, it is not a direct probability of this state. $\mathrm{P}$ value are computed based on the researchers' phenomenon that the null hypothesis is true. Consequently, the $\mathrm{p}$ value measures the compatibility of the data with null hypothesis, not the probability that the null hypothesis is correct.

In the previous chapter researchers discussed that the Philippines described as one of the highest consumption of hours in social media sites especially Facebook, and the most active users are students which adolescence are likely to spent time in social networking sites which the adults spent also more time in social interaction. Moreover, if bridging types are described as emotionally detached, bonding types are more willing to provide information about themselves which means that they want to be more connected (Ellison, Steinfeld, \& Lampe., 2007) [55]. As typical nature of bonding type as emotionally attached individuals so, they just use Facebook as a means to meet new people. As a result, there are such factors in developing the self-concept of adolescents. Wherein, cultures has an impact in developing the self-concept specifically the collectivism, whereas interdependent self-concept believe in the interconnectedness of individuals with respect to others can perceived relationship with others.

TABLE IV

Table 4 Difference of Bonding and Bridging Type in terms of Facebook Users and Self-concept

\begin{tabular}{llcll}
\hline & Social Types & t98 $_{98}$ & $\mathbf{p}$ & Interpretation \\
\hline $\begin{array}{l}\text { Facebook } \\
\text { Users }\end{array}$ & $\begin{array}{l}\text { Bonding } \\
\text { Bridging }\end{array}$ & 0.767 & 0.44 & \\
Self-Concept & $\begin{array}{l}\text { Bonding } \\
\text { Bridging }\end{array}$ & 0.940 & 0.350 & \\
& & & & \\
\hline \multicolumn{1}{c}{ Accept Ho } \\
& & & &
\end{tabular}

Based on Table 1 that mentioned earlier that bonding and bridging social capital types that has no difference at all in signifying the relationship of Facebook dependency and self-concept. Similar interpretation was concluded in the Table 4 wherein, the confidence level of $\mathrm{P}$ value $(0.05)$ is greater than the significance level that alternatively, researchers fail to reject the null or accept the null hypothesis (Ho). Further explanation about the statistical treatment, $\mathrm{p}$-value and t-value varied on the results, low pvalues were more unlikely to prove with a true null hypothesis while, high p-values were likely to reject the hypothesis. P-value of Facebook Dependency in terms of social capital types were less than than the t-test (P-value > t98), similar results were found in self-concept (P-value > t98). Therefore, there is no difference between bonding and bridging in terms of Facebook Dependency and Selfconcept.

Based on the exchangeable interaction effects of Facebook use that social capital of individuals' countenances on the resources from the different means of using the social networking sites (Putnam, 2000) [93]. Based on the result of table 3 that mentioned earlier that the used of Facebook is to meet new people without emotional connectedness whereas the similarity of the results of Facebook Dependency and Self-concept. The respondents had shown that they have moderate level in using Facebook and average level of Self-concept. It means that they both have no emotional connectedness regardless of how much they use Facebook. Thus, social capital types with or without emotional attachment, the respondents evaluate or perceives themselves that they are aware of oneself. 
The results of the study gathered by the researchers was contrary with the past studies which focuses on the relationship between the independent variables which are the social capital types that serve as indicators to the dependent variables which are the Facebook dependency and self-concept. In the study of Urista et al., (2009) [111], found that young people created a virtual identity in the means of trending ways that would impress others and could boasted one's self-concept and improving of the social capital types (bonding and bridging). Other study conducted by Hill, (2014) [125], indicated that there is a relationship with the frequency use of Facebook and self-concept.

\section{CONCLUSION}

\section{A. Conclusion}

Researchers concluded that there is a misconception about Facebook. On the previous research of Ellison, Lampe, Steinfield \& Vitak (2011) [112], was contradicting in our conclusion about the relationship of Facebook and selfconcept wherein, there is a relationship due to the factors that could affect the use of Facebook as developing the selfconcept. While, Facebook is for visual satisfying for adolescents and because adolescents have still developing their self-concept. There might be a chance that their self-concept is dynamic as the year goes by and as they are using different activities in Facebook.

Findings come up in the levels of Facebook dependency and self-concept of the respondents, it shows the big factor that could affect the level of self-concept and Facebook is the activities engaged of the individuals. On the study of Andreassen, Pallesen \& Griffths, (2014) [17], in order to labeled as a Facebook Dependent the individual shows severe dependency symptoms in order to have a formal diagnosis of Facebook dependent.

The rise of SNS addiction has been linked to the modern world of technology that helps individual to live easier, especially for communicating in social interaction. Which the researchers conclude that there is no significant relationship of Facebook dependency and self-concept of bonding and bridging of the senior high school students of Our Lady of Fatima University - Valenzuela City. That can lead to diminished sense of self-concept. Some people outflow from the consequences they encounter in real life and they would deny using Facebook in shifting their conflicts from their colleague and because of Facebook, people can hide their true identity and create a new one or something different and people often present themselves in a manner which is inconsistent with who they really are and with their set of real beliefs and values Gil-Or, Levi-Belz, Turel, (2015) [63].

Researchers concluded social media especially Facebook, for continuing establishing interaction with immediate people around the person (bonding) but also with people who only met once or virtually (bridging) that allows both types of social capital for another group of networks. Research on bonding and bridging has been shown advantages and disadvantages from getting interaction in a group of networks; bonding types provided emotional attachment, and bridging types provided different perspectives in common knowledge (Putnamn, 2000), [93]. Conversely, the result of bonding and bridging types in using Facebook as it was increases, self-concept can change the hold of cultural differences, as well in using Facebook that can be range into the activities involved and in the form of cluster of social networks or social connections.

\section{B. Limitation of Findings}

The limitations of the current study are; the researchers utilized comparative-correlational research design that determined the relationship and the difference; however the results can be limited on the evidence of norms of social capital type that can affect the results. Additionally, in terms of Facebook Dependency the researchers did not label already as a Facebook Dependent the respondents. Moreover, the instrumentation of Facebook Dependency shows only the symptoms and the range of their Facebook use that examined the whole content of the self-concept.

Researchers suggest should continue searching for specific Facebook activities that might explain the decline in selfconcept. The samples gathered are based on criteria that are age range, gender, Facebook user, and can read and write the instruments that the researchers use. Lastly, the study conducted a local norm that is only limited to the senior high school students. The future researchers may look into these factors that may affect the result of the present study.

\section{Recommendation}

Based on the results gathered, the researchers make the following recommendation:

First is for the senior high school students, the researchers encourage them to deeply understanding the social capital types as an indicator to Facebook and self-concept of senior high school students.

Second, for the educational institutions and educators, those guide the students using social networking sites, Facebook can use in assisting students to form a brief background to their personal interest and diversity to other people, and they might have the possibility fears of rejection that may further conclude why self-concept gives the impression to enhance their self-concept in spending time in Facebook or in any social networking sites, that might not in the components of bridging capital that associated in establishing emotional connectedness. Develop such activities or even teaching approach that will boost their self-concept and cope with those emotions positively.

Lastly, for the future researchers, provide a bigger number of respondents in order to assure its reliability. Aside from the variables of this present study such bonding and bridging social capital types, look for other variables.

Researchers have found that various forms or an extended version forms of social capital by the means of bonding and bridging to identify the connections of Facebook, self-concept on the social capital of the adolescence. Social networking sites has numerous users that compromise in using their accounts that can be even more better in communicating in the 
modern world, that can be also in a form of inactive socialization such as viewing individual's accounts or profiles.

Moreover, when using foreign standardized psychological test, make sure it is better to established local norms or content validation before the test administration.

\section{REFERENCES}

[1] Andreassen, Pallesen \& Griffths, (2014). The Relationship Between the Addictive use of Social Media, Narcissism, and Self-esteem: Findings from a Large National Survey. Addict Behav. 2017 Jan;64:287-293. doi: 10.1016/j.addbeh.2016.03.006. Epub 2016 Mar 19. https://doi.org/10.1016/j.addbeh.2016.03.006

[2] Arendain, J. \& Murcia, John Vianne (2016). Facebook Addiction and Aggression: Is There a Profound Relation? Retrieved from https://mpra.ub.uni-muenchen.de/72171/

[3] Ellison, N., Steinfield, C., \& Lampe, C. (2007). The benefits of Facebook "friends": Social capital and college students' use of online social network sites. J. Comput.Mediat. Communication, J. Comput.Mediat. Commun https://doi.org/10.1111/j.1083-6101.2007.00367.x.

[4] Erikson, E. (2012). The Problem of Ego Identity. Journal of the American Psychoanalytic Association, 56-121.

[5] Erikson, E. H. (1968). Identity: youth and crisis. Oxford, England: Norton \& corporation.

[6] Gil-Or, Levi-Belz, Turel, (2015). The "Facebook-self": characteristics and psychological predictors of false-presentation on Facebook.

[7] Herring, S. C. \& Kapidzic, Sanjan, (2015). Teens, Gender, and SelfPresentation in Social Media,. In-J.-D.-Wright (Ed.),International*encyclopedia*of*behavioral*sciences, ${ }^{*} 2$ nd*edition.Oxford:- Elsevier.-.

[8] Hofer, M. A. (2013). Percieved bridging and bonding social capital on twitter: Differetiating between followers and followees. Sciverse Science Direct Computers in Human Behavior.

[9] Lora, A., P. D., D. M., H. K., K. V., M. Z., . . \&. T. (2014). Testing the Validity of Social capital Measures in the Study of Information and Communication Technologies. Information, Communication \& Society, 17.

[10] Putnam, R. D. (2000). Bowling alone: The collapse and revival of American community. New York: London.

[11] Rauch, S. M. (2013). Face to Face Versus Facebook: Does Exposure to Social Networking Web Sites Augment or Attenuate Physiological Arousal Among the Socially Anxious? Education Research Journal.

[12] Steinfield, C., Ellison, N. B., \& Lampe, C. (2008). Social Capital, Self-esteem, and Use of Online Network Sites: A Longitudinal Analysis. . Journal of Applied Developmental Psychology, 434-445. https://doi.org/10.1016/j.appdev.2008.07.002

[13] Urista, M., Quinguen., \& Day, K. (2009). Exploring Why Young Adults Use myspace and Facebook through Uses and Gratification Theory. Human Communication, 215-229.

[14] Vitak, J., Zube, P., Smock, A., Carr, C., Ellison, N., \& Lampe, (2011). It's complicated: Facebook users' political participation in the 2008 election. Cyberpsychoogical Behavior Social Network, 107-114. https://doi.org/10.1089/cyber.2009.0226

[15] Hill, C. L. (2014). An Investigation of the Connectios between Use of Facebook and Self-esteem and well being of student with disability in the University of Iowa Reach Program. Retrieved from Iowa Research Online: http://ir.uiowa.edu//etal/1335

[16] Igna, H. J. (2015, March 26). National Telehealth Center. Retrieved from Internet, social media and mobile use of Filipinos in 2015: https://telehealth.ph/2015/03/26/internet-social-mediaand-mobile-use-of-filipinos-in-2015/

[17] Mcgrath, F. (2015, January 22). Globalwebindex. Retrieved from globalwebindex informs wearesocial's new Digital, Social and Mobile in 2015 Report: https://www.globalwebindex.net/blog/globalwebindex-informswearesocial-new-digital-social-and-mobile-in-2015-report
[18] Top 15 Countries based on number of facebook users. (2016, May). Retrieved from statistica.com: https://www.statista.com/statistics/268136/top-15-countries-based-onnumber-of-facebook-users.

About Author (s):

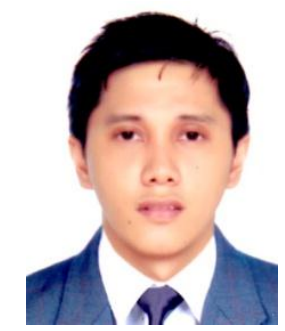

"The respondents are meeting the typical needs of an adolescent in terms of self-concept. Furthermore, it means that the adolescent are clear with their goals, values and beliefs (Erikson, 1950) which means that the respondents will have a very satisfying adulthood."

Certeza, Carlo B. - Faculty Member of Our Lady of Fatima University - Valenzuela Campus

"This study will be beneficial mostly to the students, for it will increase their awareness regarding about the Facebook usage to self-concept. Moreover, to have a broader knowledge about the social networking sites and serve this study as a valuable instruction to guide them in understanding the developing behavior change in terms of connection between the social experiences and usage."

Oli, Lovely Joy D. Oli - Student of Our Lady of Fatima Univeristy - Valenzuela Campus 